\title{
2-Nitrobenzothiophene and 3-Nitrobenzothiophene as Electrophiles in Polar Diels-Alder Reactions. Solvent effects.
}

\author{
Claudia D. Della Rosa, Maria N. Kneeteman, Pedro M.E. Mancini ${ }^{*}$ \\ Área Química Orgánica- Departamento de Química- Facultad de Ingeniería Química, Universidad \\ Nacional del Litoral. Santiago del Estero 2829. (3000) Santa Fe, Argentina. \\ FAX: +54-342-4571162. *e-mail:pmancini@fiq.unl.edu.ar
}

\begin{abstract}
In this work the polar Diels-Alder reactions between 2- and 3-nitrobenzothiophenes derivatives and different dienes such as 2-methyl-1,3-butadiene and 1-trimethylsilyloxy-1,3butadiene are studied. Molecular solvent and protic ionic liquids are employed as reaction media. The presence of a very strong electron-acceptor group such as nitro, improve the electrophilic character of these heterocyclic compounds. Moreover, this substituent is easily extruded under thermal conditions make this reaction sequence a simple method of organic compound families with heteroatom rings preparation.
\end{abstract}

Keywords: nitrobenzothiophene, electrophile, ionic liquid, Diels-Alder

\section{Introduction}

The Diels-Alder (DA) reaction is one of the most significant and useful tools available in synthetic chemistry. This reaction provides the chemist with one of the best methods for the preparation of cyclic and heterocyclic aromatic compounds. ${ }^{1}$

In the 1980s, studies on cycloaddition reactions of carbonyl or carboxyl substituted aromatic heterocycles such as indoles, benzofurans, pyrroles, furans, and thiophenes demonstrated the viability of these aromatic systems as dienophiles. Further studies focused on the dienophilic character of indoles since their adducts seemed to be appealing for the total synthesis of carbazole and Aspidosperma alkaloids. ${ }^{2}$

In the last years we reported the electrophilic behavior of different monocyclic five- membered nitroheteroaromatic compounds properly mono and disubstituted in their exposure to different dienes under thermal conditions, using as solvent molecular ones and ionic liquids, respectively. ${ }^{3,4}$

Moreover, we use as electrophiles in this type of polar DA (P-DA) reactions a serie of benzofused five-membered nitroheteroaromatic compounds, such as nitrobenzothiophenes. A very strong electron-acceptor group, such as nitro group, push the dienophilic character of these heterocyclics and owing to this substituent is easily extrused under thermal conditions makes this reaction sequence a simple method of organic compound families with heteroatom rings preparation.

In general, these cited polar cycloadditions are a domino process that is initialized by a D-A reaction to give the formally [4 +2 ] cycloadduct followed for the subsequent concert irreversible elimination of nitrous acid, which is the factor responsible for the feasibility of the overall process. In particular, for polar D-A reactions one of the most interesting aspects is its solvent dependence. Moreover, in recent years, this reaction has been subject of several studies in order to enhance the reactivity. For specific D-A reactions was demonstrated that the aqueous solutions have remarkable increase in reactivity and selectivity, and these results were discussed 
in terms of hydrophobic effects. Ionic liquids (ILs) with similar properties to water, such as being highly ordered media and good hydrogen bonding donor (HBD), have also been shown to have potential influence the outcome of polar D-A reactions.

The aim of the present work is twofold, considering the results obtained in the thermal polar D-A reactions of nitrobenzothiophenes and dienes using molecular solvents as reaction media, the first purpose is to analyze the influence of room temperature ionic liquids (RTILs) in this type of polar cycloaddition reactions in which the electrophile are relatively poor. With this purpose, ammonium- and imidazolium-based ILs have been selected because the differences in their HBD acidity. In general, it would be possible demonstrated that the ILs solvent effect in these reactions is in general determined by the solvent hydrogen bond donation ability.

\section{Results and discussion}

The electrophiles used were 2-nitrobenzothiophene (1a), 3-nitrobenzothiophene (1b). On the other hand 2-Methyl-1,3-butadiene (2) and 1-Trimethylsilyloxy-1,3-butadiene (3) were chosen as diene partners (Scheme 1).

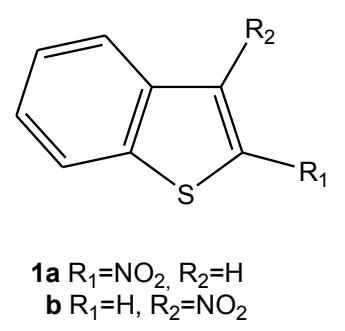

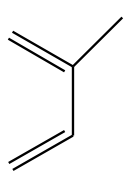

2

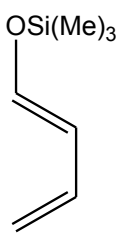

3

\section{Scheme 1}

To complete the reaction approach of benzothiophenes substituted with electron with-drawing groups as electrophiles, we have investigated PILs solvent effects in polar D-A reactions using ethylammoniun nitrate (EAN), and 1-methylimidazolium tetrafluoroborate ([HMIM][BF $]$ ). Preparation of EAN) and 1-methylimidazolium tetrafluoroborate ([HMIM][BF $]$ ) followed the published methods. ${ }^{5}$

This allowed us compared in thermal cycloaddition reaction conditions not only the relative reactivity of these substrates also the regioselectivities when we change molecular solvents for ILS.

The thermal reactions of 2-nitrobenzothiophene 1a with 2 in a sealed ampoule at $120{ }^{\circ} \mathrm{C}$ or 150 ${ }^{\circ} \mathrm{C}$ for $72 \mathrm{~h}$ using benzene as solvent afforded the pyrrolyl derivative 4 as unique product. ${ }^{7}$ This unexpected behaviour was also found with nitronaphthalenes as dienophiles. ${ }^{6}$ Likewise exposure of $1 \mathrm{a}$ to diene $\mathbf{3}$ produced the dibenzothiophene $\mathbf{5}$ with good yield (Scheme 2).

Similarly, in the reactions employing benzene as reaction media under thermal conditions of 3nitrobenzothiophene $\mathbf{1 b}$ with $\mathbf{2}$ the corresponding pyrrolyl-benzothiophene $\mathbf{6}$ are obtained and the dibenzothiophene $\mathbf{5}$ with good yield when reacted with diene $\mathbf{3}$ (Scheme 3). 

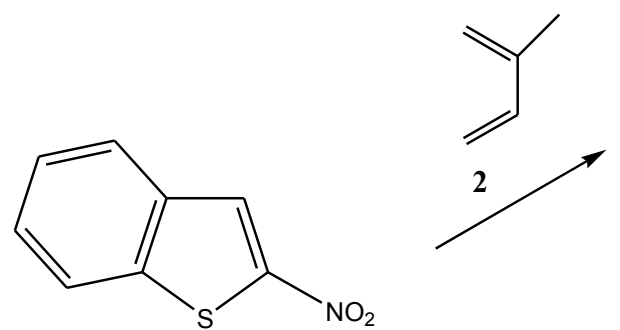

$1 \mathbf{a}$

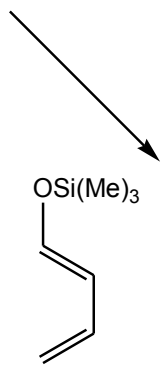

3

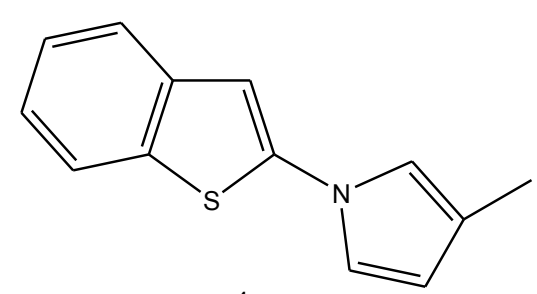

4

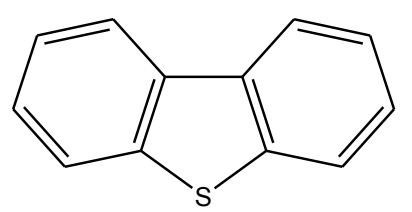

5

\section{Scheme 2}

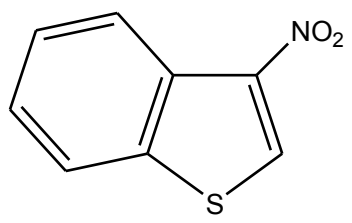

1b
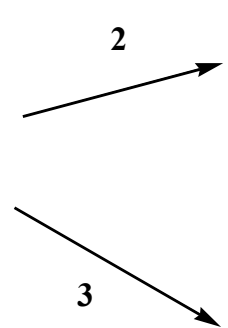

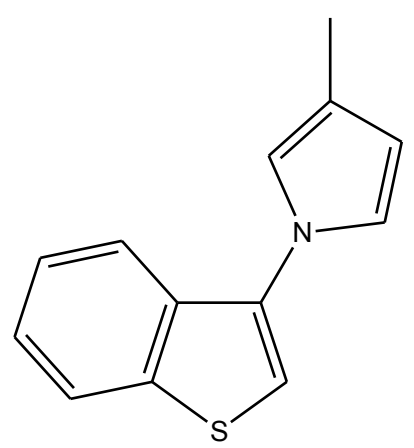

6

\section{Scheme 3}

The reactions of $1 \mathrm{a}$ with isoprene 2 using EAN or [HMIM][BF 4$]$, respectively, as solvents in seals ampoule at $60^{\circ} \mathrm{C}$ (12 and $24 \mathrm{~h}$, respectively) offered in all cases pyrrolyl derivative 4 . The best yield (ca. 60\%) was obtained with EAN as solvent working $24 \mathrm{~h}$.

The reaction of diene $3\left(60^{\circ} \mathrm{C}, 12\right.$ and $24 \mathrm{~h}$, respectively) with 1a using the two IL's cited in the before paragraph yielded dibenzothiophene in reasonable yield.

Similarly, reactions of $\mathbf{1 b}$ with isoprene using EAN or [HMIM][BF 4 respectively, as solvents in seals ampoule at $60^{\circ} \mathrm{C}\left(12\right.$ and $24 \mathrm{~h}$, respectively) produced the pyrrolyl derivative 6 (Scheme 3). ${ }^{7}$ In turn the reactions with $\mathbf{3}$ offer the product $\mathbf{5}$ with good yield. 
In all cases the presence of ILs as reaction media improve the yields respect to use of molecular solvent, while the temperature and reaction time decrease. The presences of the IL do not change the type of products in the reactions respect the use of molecular solvent. In this last sense the diene nucleophilicity would be responsible of the product obtention.

\section{Acknowledgments}

This research was supported by CAI+D 2011-66-069 at Universidad Nacional del Litoral, Santa Fe, Argentina.

\section{References and notes}

1. For general rewiew, see: (a) W. Carruthers in Cycloaddition Reactions in Organic Snthesis, Pergamon Press, Oxford, UK, 1990; (b) F. Fringelli, A. Tatichi in The Diels-Alder Reaction, J. Wiley \& Sons, Chichester, UK, 2002; (c) E.J. Corey, Angew. Chem. Int. Ed., 41, 1650-1667, 2002.

2. a) E. Wenkert, P. Moeller, S. Piettre, J. Am. Chem. Soc.1988, 110, 7188; b) E. Wenkert, S. Piettre, J. Org. Chem., 1988, 53, 5850.

3. a) B. Biolatto, M. Kneeteman, P. Mancini, Tetrahedron Lett. 1999, 40, 3343; b) B. Biolatto, M. Kneeteman, E. Paredes, P.M.E. Mancini, J. Org. Chem. 2001, 66, 3906. c) C. Della Rosa, M.N. Kneeteman, P.M.E. Mancini, Tetrahedron Lett. 2007, 48, 1535.

4. a) C. Della Rosa, C. Ormachea, M.N. Kneeteman, C. Adam, P.M.E. Mancini. Tetrahedron Lett. 2011, 52, 6754. b) C.D. Della Rosa, C.M. Ormachea, A. S. Sonzogni, M. N. Kneeteman, L. R. Domingo, P. M. E. Mancini, Lett. In Org. Chem. 2012, 9, 691.

5. E. Janus, I. Goc-Maciejewska, M. Lozynski, J. Pernak. Tetrahedron Lett. 2006, 47, 4079.

6. P. M. E. Mancini, C. D. Della Rosa, C. M. Ormachea, M. N. Kneeteman, L. R. Domingo. RCS Advances 2013, 3, 13825.

7. General Procedure. An ampoule containing $1.0 \mathrm{mmol}$ of the dienophile and the required amount of diene in $1 \mathrm{ml}$ of molecular solvent or ionic liquid was cooled in liquid nitrogen, sealed and then heated with stir in a bath. After the reaction time was completed, it was cooled once more in liquid nitrogen and opened. After separation of the phases, the organic phase was evaporated and the residue purified by column chromatography in silica gel or alumina using hexane/ethyl acetate mixtures as eluent. 